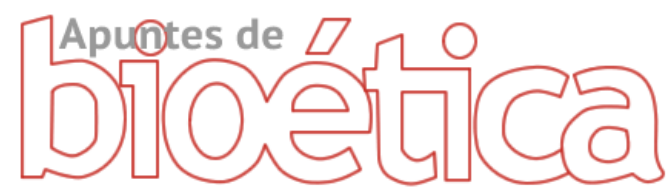

https://doi.org/10.35383/apuntes.v2i1.240

\title{
Bioética, persona y familia: una bioética que humaniza
}

\author{
Kathya Lisseth Vassallo Cruz ${ }^{1}$
}

INFORMACIÓN DEL ARTÍCULO RESUMEN

Historia del artículo:

Recibido el 20 de marzo de 2019

Aceptado el 25 de julio de 2019

\section{Palabras claves:}

Bioética

Dignidad

Humanización

Familia

En las últimas décadas, se ha percibido el influjo de posturas, y se ha evidenciado corrientes reduccionistas que han vaciado de contenido a la Bioética y afectado su ejercicio. Es a través de la exigencia de la valoración ontológica de la persona que se llega a constituir el fundamento necesario para una adecuada práctica de la Bioética, en una imperiosa necesidad de rescatar y reponer las bases éticas originarias de la persona de las cuales debe partir la toma de decisiones bioéticas que repercuten y redundan en el ser humano, la familia, las generaciones futuras y el ambiente.

\section{Bioethics, person and family: A Bioethics that humanizes}

\section{ABSTRACT}

\section{Keywords:}

Bioethics

Dignity

Humanization

Family
In recent decades, the influence of postures has been perceived, and reductionist currents have been evidenced that have emptied content to Bioethics and affected its exercise. It is through the requirement of the ontological assessment of the person that it becomes the necessary foundation for an adequate practice of Bioethics, in an imperative need to rescue and replenish the original ethical bases of the person from whom the Bioethical decision making that affects and results in the human being, the family, future generations and the environment.

\footnotetext{
1 Abogada y Maestro en Derecho de Familia y de la Persona, docente de la Facultad de Derecho y miembro del Instituto de Bioética y del Instituto de Ciencias para el Matrimonio y la Familia de la Universidad Católica Santo Toribio de Mogrovejo, Lima, Perú. Email: kvassallo@usat.edu.pe. ORCID: https://orcid.org/0000-0002-6009506X
} 


\section{Bioética: eclipse o amanecer de la humanidad}

La Bioética es un término que ha cobrado especial relevancia en la actualidad, y si bien su uso se ha visto acentuado con el devenir de las últimas décadas, su contenido -la ética de la vida- ha estado presente a lo largo de la existencia humana. La palabra Bioética fue presentada por V. R. Potter como una disciplina del saber con especial atención en la supervivencia de la humanidad, de allí su conexión y significativa relación con las ciencias. Es así como, "La sencilla y etimológica definición de Potter evolucionó hasta tener un carácter pluridisciplinario. Desde entonces la Bioética ha ido creciendo como cuerpo teórico y se ha robustecido como discurso" (Molina Ramirez, 2011, pág. 111) constituyéndose en un puente entre ética y ciencia.

Sin duda, se trata de una realidad que nos acompaña, pero también es cierto que en el caminar de estos últimos tiempos se ha vislumbrado una suerte de alejamiento de su contenido esencial. Se ha puesto en evidencia una preocupante carencia antropológica en su contenido, afectado por los rasgos sociales a los que actualmente nos enfrentamos y que se encuentran alejados de una supervivencia solidaria de la humanidad y de lo éticamente correcto.

En palabras de L. M. Pichardo (2018):

“La bioética atraviesa un momento difícil en medio de una sociedad que parece huir muy rápidamente de los verdaderos valores éticos y humanísticos. EI posthumanismo presenta un nuevo modelo del ser humano, uno que prescinde de los principios y conceptos que han sido empleados hasta ahora por la humanidad. El discurso en bioética presenta este modelo sin ninguna relación con la antropología que se ha utilizado durante siglos y lo hace de una manera que carece totalmente de referencias éticas. Estas disimilitudes reflejan una perspectiva académica mal representada que pertenece a una era posterior a la verdad... Cuando se trata de la toma de decisiones sobre los llamados dilemas bioéticos, presenta una nueva versión biotecnológica del hombre que prevalece sobre la salud real y las preocupaciones biológicas que deben resolverse". (p. 213)

Esto lleva al surgimiento de corrientes, que no apuestan por trascender desde lo humano, por el contrario, se van alejando por falsos ideales que desnaturalizan, en una suerte de escindir lo esencialmente humano. Hoy se habla de transhumanismo, posthumanismo y lo sobrehumano, en un intento por transformar al ser humano e incluso superarlo.

Trasgredir lo humano, es consecuencia de un dominio desordenado del hombre sobre el mundo, que lo enceguece y desenfoca de la toma de decisiones éticas. El hombre no está en una posición de mero espectador de su entorno, forma parte de éste y tiene deberes aparejados a su capacidad de dominio y situación de poder.

Justamente para el hombre, "la reflexión sobre la necesidad de que ese domino no se vuelva en su contra, es precisamente uno de los factores que despiertan su interés por regular su comportamiento" (Franco, 2007, pág. 129), cobrando especial importancia la práctica de una Bioética, al margen de reduccionismos utilitaristas, procedimentales o economicistas que deshumanizan y apartan al hombre del bien común.

\section{Exigencia de una valoración ontología de la persona}

Lo que constituye a la persona en alguien y no en algo, es la dignidad humana. Si duda, la 
persona por su valor intrínseco, reclama ser tratada de un modo no instrumental, "manipular la persona humana en alguno de sus aspectos puede significar una pretensión de dominio directo sobre ella, traspasando los límites éticos y metafísicos, adjudicándonos indebidamente una función creadora de la que carecemos por naturaleza y que nos excede sobremanera" (Agulles Simó \& Gillén Pascual, 2011, pág. 142).

Por ello, nuestro ser reclama el reconocimiento de su propio valor, rechazando ser tratado como objeto de trasgresiones, producto de una fantasía o inventiva vaciada de contenido, "[I]a persona reclama ser descubierta en su valor y no inventada fantásticamente. La persona es una realidad, no un mero fenómeno virtual" (Guerra López, La persona es fin y no medio..., 2007, pág. 47).

En palabras de E. Sgreccia (2014): “Entre el cuerpo humano y la cosa subsiste un salto ontológico y cualitativo inconmensurable. Sobre dichas bases filosóficas se funda la consideración negativa de la 'mercantilización' del cuerpo" (pág. 162).

El ser humano no puede ser tratado como cosa, se es persona con una dignidad inherente. De Mestral indica que:

"La dignidad tiene un valor intrínseco, independiente de su desarrollo, de su éxito o fracaso. No se está frente a algo, sino frente a alguien. Todos los humanos somos personas, al margen de cualquier cualidad presente o ausente. La dignidad humana es la dignidad de un ser que es fin en sí mismo, por ser persona" (De Mestral, 2014, pág. 32).

Es debido a la dignidad del ser, que el hombre puede descubrirse y conocerse, sin menoscabar ni tratar como medios a los demás miembros de la familia humana.
A decir de A. Aparisi Miralles (2013): "Precisamente, cuando se comprende que de la dignidad humana, y de su defensa, depende, en gran medida, el destino mismo del hombre, se puede vislumbrar la importancia de tener siempre viva y activa la reflexión en torno a la misma" (pág. 205). La persona y su humanidad no se alcanza a comprender si no se reconoce su valor trascendente ${ }^{2}$, que constituye su ser $y$ deber ser.

Debe tenerse presente que "[n]o es lo mismo ser humano, que vivir y comportarse humanamente" (Carlos Bermejo, 2014), por eso estamos llamados en términos de deber, a accionar de acuerdo con nuestra condición específica en la toma de decisiones bioéticas.

La vida humana es invaluable, y su respeto inclina al hombre hacia la valoración de la vida en general.

\section{Antropocentrismo espectador o Personalismo responsable}

El autor J. López Guzmán (2013) hace una especial indicación en lo relacionado a la enseñanza de la Bioética, y es que: "El problema surge cuando todo el proceso formativo se articula en torno a los casos prácticos, con una carencia de presupuestos filosóficos y antropológicos que convierte en estéril y relativa cualquier discusión o debate" (págs. 87 y 88) ello ocasiona el ingreso de reduccionismos o corrientes que alejan al hombre de su ser y deber ser, dejándose llevar por la propia voluntad o sumiéndolo en las ansias de poder, no midiendo las consecuencias en detrimento

\footnotetext{
${ }^{2}$ Cabe indicar que "valor es todo lo que permite dar un significado a la existencia humana, todo lo que permite ser verdadero hombre (...) Las cosas adquieren valor en la medida en que se insertan en ese proceso de humanización del hombre" (Gevaert citado por Carlos Bermejo, 2014).
} 
del otro, del más desvalido 3 , de las generaciones futuras $y / o$ de la naturaleza.

Caer en una suerte de antropocentrismo espectador, sin compromiso y poco involucrado con el mundo, acarrea una falta de respeto y responsabilidad hacia el hombre, los demás seres vivos y nuestro entorno.

A decir de E. Postigo Solana (2007):

"Los problemas de nuestro tiempo son debido, no al progreso tecnológico en sí mismo, sino a la ausencia de un progreso simultáneo en la dimensión filosóficosapiencial (...) pérdida de percepciones antropológicas y éticas que constituyen el corazón y punto de partida de la reflexión moral" (págs. 36 y 37).

Lo que demanda que la toma de decisiones bioéticas parta de una sólida antropología y filosofía personalista, para determinar: el progreso en justa medida, garantizar el bienestar de la humanidad y el respeto de la vida.

A lo antes expuesto, cabe sumar lo manifestado por R. Guerra López (2013), quien señala:

"El personalismo se encuentra al servicio de la ampliación del horizonte de la razón al momento de fundamentar la bioética. Este servicio no es menor. La razón arrogante típica de la modernidad ilustrada ha cedido en muchos ambientes a una razón exhausta que ya no desea preguntar, investigar y descubrir esencias,

\footnotetext{
${ }^{3} \mathrm{EL}$ documento de Pautas Éticas Internacionales para la Investigación Biomédica en Seres Humanos preparado por el Consejo de Organizaciones Internacionales de las Ciencias Médicas (CIOMS) en colaboración con la Organización Mundial de la Salud, indican como una de las dos consideraciones éticas fundamentales del principio de respeto de la persona, la "(...) protección de las personas con autonomía disminuida o deteriorada, que implica que se debe proporcionar seguridad contra daño o abuso a todas las personas dependientes o vulnerables." (CIOMS, 2002)
}

sino que se conforma con describir y con articular equilibrios de poder entre diversas cosmovisiones. Este tipo de racionalidad debilitada es sumamente susceptible de tornarse violenta, despótica, asesina. Desde este punto de vista, la misión de la bioética personalista es fundamental para contribuir a la supervivencia de nuestras sociedades y para la auténtica promoción del bien común" (pág. 47)

El ser humano debe recuperar los espacios de reflexión de la recta razón práctica en su obrar y en la resolución de dilemas bioéticos, de la mano del personalismo que se hace responsable del hombre y su entono. Visto de esta forma, la Bioética se torna en una real disciplina que contribuye en bien de la humanidad y la vida.

\section{Progreso implica crecer en Humanidad}

Respecto a los avances de la ciencia, el hombre y la naturaleza, la Declaración Universal sobre Bioética y Derechos Humanos aprobado por la Organización de las Naciones Unidas para la Educación, la Ciencia y la Cultura UNESCO (2005), indica que:

\section{"Artículo 16 - Protección de las generaciones futuras}

Se deberían tener debidamente en cuenta las repercusiones de las ciencias de la vida en las generaciones futuras, en particular en su constitución genética.

Artículo 17 - Protección del medio ambiente, la biosfera y la biodiversidad

Se habrán de tener debidamente en cuenta la interconexión entre los seres humanos y las demás formas de vida, la importancia de un acceso apropiado a los recursos biológicos y genéticos y su utilización, el respeto del saber tradicional y el papel de los seres humanos en la 
protección del medio ambiente, la biosfera y la biodiversidad". (UNESCO, 2005)

El avance y el progreso, responden a un llamado por conseguir adelantos en el conocimiento del hombre y del lugar en el que habita.

Si bien "[e]l crecimiento exponencial del conocimiento científico por una parte, y por otra, la ausencia de una sabiduría de cómo manejarlo, han colocado al ser humano en una situación donde la vida se encuentra profundamente comprometida" (González López, 2012, pág. 56), nos permite comprender que no se trata solo de obtener la mayor información, sino de conocer la naturaleza del hombre y lo que yace inscrito en su ser personal, aquello que le permita ser más humano y hacer del mundo algo mejor. Progresar, implica crecer en humanidad (Postigo Solana, 2007), todo lo que esté en contra, pone en juego al hombre actual, las generaciones futuras y el orden natural.

La Bioética llega a adquirir significado, en la medida que, sabiamente su práctica se torne parte y contribuya en el proceso de humanización del hombre, comprendido no de un modo antropocéntrico desligado del mundo, sino como un ser digno responsable y partícipe de la naturaleza.

La experiencia humana lo evidencia y lo afirma, la bioética al ingresar en el campo práctico requiere que las decisiones éticas partan del compromiso existencial del ser humano: con el mismo, con el otro y la naturaleza.

\section{La familia: pieza clave del engranaje social y bioético}

Se debe reconocer que, entre la persona y la humanidad existe una célula dinámica de especial y trascendente importancia, que viene siendo lesionada: la familia ${ }^{4}$. Es un hecho que:

"[e]l hombre se ha venido haciendo independiente de lo que le rodea, pero a la vez se va creando necesidades cada vez más suntuarias y hasta ridículas, se va convirtiendo en un depredador consumista, va perdiendo la conciencia de cuidado; ha sustituido la idea de mantenimiento por la de progreso, la de administración por la propiedad, la de necesidad por capricho, la de responsabilidad por autonomía. Todo esto afecta no solo a las personas individuales sino también a las familias, haciéndolas cada vez vulnerables" (Gamboa-Bernal, 2016, pág. 399).

Es preocupante y ha llamado mucho la atención la situación propia de la familia, hace unas décadas atrás era catalogada como célula básica de la sociedad, defendida e invocada en todos los estrados, así como reconocida y protegida por la ley y la justicia sin mayor cuestionamiento; pero, esta armónica situación de la familia ha cambiado en la actualidad, siendo mellada, manipulada y vista como un obstáculo para la superación individualista y selectiva que propugna un avance sin medidas y límites.

Pese a las dificultades presentadas, la familia:

\footnotetext{
${ }^{4}$ La familia se encuentra "...universalmente aceptada como unidad básica de la sociedad, independientemente de sus formas u organización, constituye en todas partes del mundo, el espacio natural y el recinto micro social para el desenvolvimiento de sus miembros. En tanto institución que mediatiza la interacción individuo - sociedad - familia, está sensiblemente conectada a la dinámica social y a las realidades históricas diversas en el devenir de los distintos estadios de su ciclo vital. Además, está dotada de enorme flexibilidad, de una suerte de metamorfismo y de insospechados mecanismos de adaptación a las condiciones cambiantes del medio material, de la organización del trabajo, de los procesos económicos, de los avances tecnológicos, así como de las estructuras abstractas de la sociedad, la ideología, los valores, las normas, los representativos simbólicos". (Valladares González, 2008, pág. 9).
} 
"(...) como institución y grupo la familia conserva su vigor, continúa cumpliendo importantes funciones para con la sociedad y para con sus miembros, constituye un bastión indiscutible para la conservación de nuestra identidad cultural, por supuesto, reclama respeto, atención y una participación más activa en la toma de decisiones de todo lo que directamente le concierne". (Valladares González, 2008, pág. 7).

Sin duda, la familia se presenta desde siempre como una institución fundamental que ha sabido superar los retos que se han presentado a lo largo de la historia de la humanidad, contribuyendo y favoreciendo la ecología humana, aquella que comprende la interacción humana y su relación con el ambiente, y de la cual depende la vida de las generaciones futuras y la promoción del bien común.

La Declaración Universal de los Derechos Humanos, en el inciso 3 del artículo 16, reconoce a la familia como "el elemento natural y fundamental de la sociedad y tiene derecho a la protección de la sociedad y del Estado", y en su preámbulo se le reconoce íntimamente ligada a la dignidad intrínseca del ser humano y sus derechos. La familia, sin lugar a duda, se constituye en un eslabón clave dentro de la sociedad y en la vida de cada persona, reconociéndosele grandes responsabilidades y contribuciones de sumo significativas para bien de la sociedad y el bien común, por eso y más, se hace presente la necesidad de que sea atendida, considera, reconocida, debiéndose procurar una especial protección.

A decir de G. Gamboa-Bernal (2016):

“La primera y principal estructura humana es la familia y desde ella se puede encauzar el rumbo para que la interacción hombre y medio ambiente sea de mutuo beneficio; se puedan corregir a tiempo los excesos infringidos a la naturaleza, que ponen en riesgo el futuro del planeta y de la misma especie humana y cambiar la actual cultura de la muerte por una cultura donde la vida sea respetada, protegida, promovida, valorada y adecuadamente cuidada cuando esté en peligro (...) el futuro de la humanidad pasa necesariamente por la familia, o en otras palabras, el bien de la familia es decisivo para el futuro del mundo." (págs. 392-393).

Tener sobre la mesa de debate o toma de decisiones bioéticas, a la familia, es de sumo importante y relevante para bien de la humanidad y la vida en sus diversas manifestaciones. Las cuestiones de vida indiscutiblemente involucran a la familia, por lo que, ignorarla pone en riesgo a la especie humana y el lugar en el que habita.

La familia no se trata de una institución que pueda colocarse o desecharse del ojo de la Bioética de un modo antojadizo, la Declaración Universal sobre Bioética y Derechos Humanos en su preámbulo, indica que:

"[los] adelantos deben procurar siempre promover el bienestar de cada individuo, familia, grupo o comunidad y de la especie humana en su conjunto, en el reconocimiento de la dignidad de la persona humana y en el respeto universal y la observancia de los derechos humanos y las libertades fundamentales (...) Reconociendo asimismo que las decisiones relativas a las cuestiones éticas relacionadas con la medicina, las ciencias de la vida y las tecnologías conexas pueden tener repercusiones en los individuos, familias, grupos o comunidades y en la especie humana en su conjunto". 
Es la familia aquella que se encuentra involucrada con el desarrollo de la persona, el progreso de la humanidad y la situación de nuestro entorno. Como se indica en el texto de la Declaración, el adelanto de la ciencia no puede ignorar a la familia, las cuestiones éticas que acompañan pueden llegar a repercutir en la familia, por ello el especial énfasis de que todo adelanto procure el bienestar de la familia.

Es lamentable, pero en nombre del "progreso" se ha envuelto a la familia en dilemas y cuestionamientos bioéticos, cuyo análisis se aleja de una visión personalista o simplemente no detiene la mirada, me refiero a los relacionados con el "(...) procesos de la procreación, la defensa de la vida naciente, los cambios en la paternidad (la nueva paternidad múltiple), la definición de la muerte y la asistencia al moribundo, la estructura intergeneracional y demográfica de la familia". (Sgreccia, La bioética hoy y la repercusión en el campo del matrimonio y de la familia, 1994, pág. 91). Se debe asumir de modo crítico lo que ingresa en el plano de la bioética y su repercusión en la familia.

Si en el camino recorrido en nombre de la ciencia, se ha venido postergando a la familia, el grupo de fenómenos generados en su trayecto amenaza no solo la vida afectiva de la persona, sino que torna carentes los sustratos mínimos para que la familia sea constituida de un modo adecuado, viéndose disminuida en su solidaridad y capacidades para brindar los apoyos necesarios, auténticos y duraderos a sus integrantes, haciendo que la persona desconozca sus fines y se vea aprisionado por los confinamientos del egoísmo, que lo llevan a ensimismarse y ser incapaz de replicar la familia, tejido social de la humanidad a la cual se le atribuye la enriquecedora convivencia humana, que lejos de pasar de moda, es la firme salvaguarda para asegurar el futuro, en términos de ayuda mutua5. (Gamboa-Bernal, 2016, págs. 395 y 397)

Los tiempos que nos ha tocado vivir, exige que:

"La bioética se ha constituido como nueva rama del saber ético con repercusión en el ámbito de la familia. En cuanto tal, proporciona un ámbito teórico-práxico especial para abordar problemas éticos antiguos y nuevos relacionados con la vida humana y su relación con los modelos familiares. En la génesis de la bioética han influido, y siguen influyendo, un conjunto de factores que han dejado, y siguen dejando, su peculiar impronta en la configuración de esta nueva área de la interdisciplinariedad científica y las ciencias de la familia (...) Estamos asistiendo a una realidad presente con un futuro totalmente incierto e imprevisible para la familia, de ahí la tarea consistirá en diseñar un horizonte axiológico donde se puede orientar humanamente la nueva civilización" (Parada Navas, 2010, págs. 197 y 201).

Únicamente, dando significado a la existencia humana, reconociendo su valor ontológico en el proceso de humanización y respetando a la familia, puede rescatarse a la bioética de un "estar a la deriva" en las reflexiones éticas, que nada aporta a la humanidad y el mundo en el que se encuentra.

\section{Conclusiones}

El fundamento de la persona es la dignidad humana, y el fundamento de la sociedad es la

\footnotetext{
${ }^{5}$ Es incuestionable que "[u]na gran parte de la vida social se articula en torno a la familia y en su influencia ad intra y ad extra. La familia sigue siendo el fundamento de la solidaridad que, en casos de necesidad, teje una sólida red de ayudas que permiten afrontar las dificultades y problemas que continuamente surgen en la multiforme sociedad en la que vivimos: penurias económicas, enfermedades, crianza de los hijos, problemas de alcoholismo, drogas,..." (Parada Navas, 2010, pág. 200).
} 
familia, aquella donde el hombre nace, se forma y desarrolla en comunidad.

En el seno de una familia saludable la humanización de la persona, la sociedad y su entorno es posible, solo en ella el ser humano puede llegar a descubrirse como persona.

En lo concerniente a las lesiones infringidas, a la familia se le debe: reconocer la importancia que lleva implícita, ayudarla a tomar conciencia de sus dificultades, problemas y limitaciones, reparar y enmendar los errores cometidos y sobre todo respetarla.

No todo lo técnicamente posible es éticamente correcto, y al cometerse equivocaciones en contra de lo humano, deben ser corregidas y enmendadas a través de soluciones verdaderamente humanas, a la luz de su ser y de una bioética interdisciplinaria que responda a las consideraciones antropológicas y éticas de la persona vista de un modo integral, como miembro de una familia, forjadora de la humanidad y partícipe de un entorno del cual es responsable hoy y para las generaciones futuras.

\section{Bibliografía}

Agulles Simó, P., \& Gillén Pascual, M. (2011). Ética de la Investigación Biomédica: Trasplantes, Vacunas y Embriones. España: Editorial cultural y espiritual popular.

Aparisi Miralles, Á. (mayo-agosto de 2013). El principio de la dignidad humana como fundamento de un bioderecho global. Cuadernos de Bioética, 24(81), 201-221.

Carlos Bermejo, J. (2014). Humanizar la asistencia sanitario. Portugal: Desclée de Brouwer S.A.
Centro de Humanización de la Salud. (2008). Manual para la humanización de los gerocultores y auxiliares geriátricos. España: Cáritas Española.

Consejo de Organizaciones Internacionales de las Ciencias Médicas-CIOMS. (2002). Pautas Éticas Internacionales para la Investigación Biomédica en Seres Humanos. Ginebra.

De Mestral, E. (2014). Ser persona. En E. De Menestral (Ed.), Manual de Bioética (4 ed., págs. 31-34). Paraguay: EFACIM.

Franco, L. (2007). Bioética y solidaridad. En G. M. Tomás y Garrido, \& M. E. Postigo Solan (Edits.), Bioética personalista: ciencia y controversias (págs. 129-147). España: Ediciones Internacionales Universitarias.

Gamboa-Bernal, G. A. (2016). La familia: un desafío para el futuro de nuestra tierra. Cuadernos de Bioética, 3(27), 391-402.

González López, I. (enero-junio de 2012). Van Rensselaer Potter y Edgar Morin: cambios en el pensamiento ético contemporáneo. Revista Latinoamericana de Bioética, 12(1), 46-61.

Guerra López, R. (2007). La persona es fin y no medio. El fundamento normativo de la bioética personalista. En G. M. Tomás y Garrido, \& M. E. Postigo Solan (Edits.), Bioética personalista: ciencia $y$ controversias (págs. 39-69). España: Ediciones Internacionales Universitarias.

Guerra López, R. (enero-abril de 2013). Bioética y Racionalidad. El personalismo al servicio de la ampliación del horizonte de la razón en la fundamentación Bioética. Cuadernos de Bioética, 24(1), 39-48. 
López Guzmán, J. (enero-abril de 2013). La bioética personalista en los planes de estudio universitario. Cuadernos de bioética, 24(1), 79-90.

Molina Ramirez, N. (julio-diciembre de 2011). ¿Qué es la bioética y para qué sirve? . Revista Colombiana de Bioética, 6(2), 110-117.

Organización de las Naciones Unidas para la Educación, la Ciencia y la CulturaUNESCO. (2005). Declaración Universal sobre Bioética y Derechos Humanos.

Organización de Naciones Unidas-ONU. (1948). Declación Universal de Derechos Humanos.

Parada Navas, J. L. (2010). Las investigaciones bioéticas "pensar" en la familia. Verdad y vida: revista de las ciencias del espíritu, 68(256), 197-226.

Pichardo, L. M. (2018). Reinventar la bioética en una sociedad posthumanista y de posverdad. El presente y futuro de la bioética. Persona y Bioética, 22(2), 212222.
Postigo Solana, E. (2007). Conceptos de bioética y corrientes actuales. En G. M. Tomás y Garrido, \& M. E. Postigo Solan (Edits.), Bioética personalista: ciencia y controversias (págs. 18-38). España: Ediciones Internacionales Universitarias.

Sgreccia, E. (enero-julio de 1994). La bioética hoy y la repercusión en el campo del matrimonio y de la familia. Cuadernos de Bioética, 2(17-18), 88-95.

Sgreccia, E. (2014). Manual de Bioética: Fundamentos y ética biomédica (4 ed.). (P. Cervera Barranco, Trad.) España: Biblioteca de Autores Cristianos.

Valladares González, A. M. (2008). La familia. Una mirada desde la Psicología. Revista Electrónica de las Ciencias Médicas en Cienfuegos(6), 4-13. 